\title{
THE McGREGOR BUILDING AND TOWER TELESCOPE OF THE MCMATH-HULBERT OBSERVATORY
}

\author{
By Dr. Robert R. McMath
}

$\mathrm{W}^{1}$

ITH the dedication of the new McGregor Building and Tower Telescope on May 25, 1940, the McMath-Hulbert Observatory of the University of Michigan became perhaps the most complete and powerful installation on earth for
To minimize any risk from vibration, the tower und its foundations are of unusually massive construction throughout. Actually, the tower consists of two steel shells, one within the other. The outer tower carries the dome, the floors and other

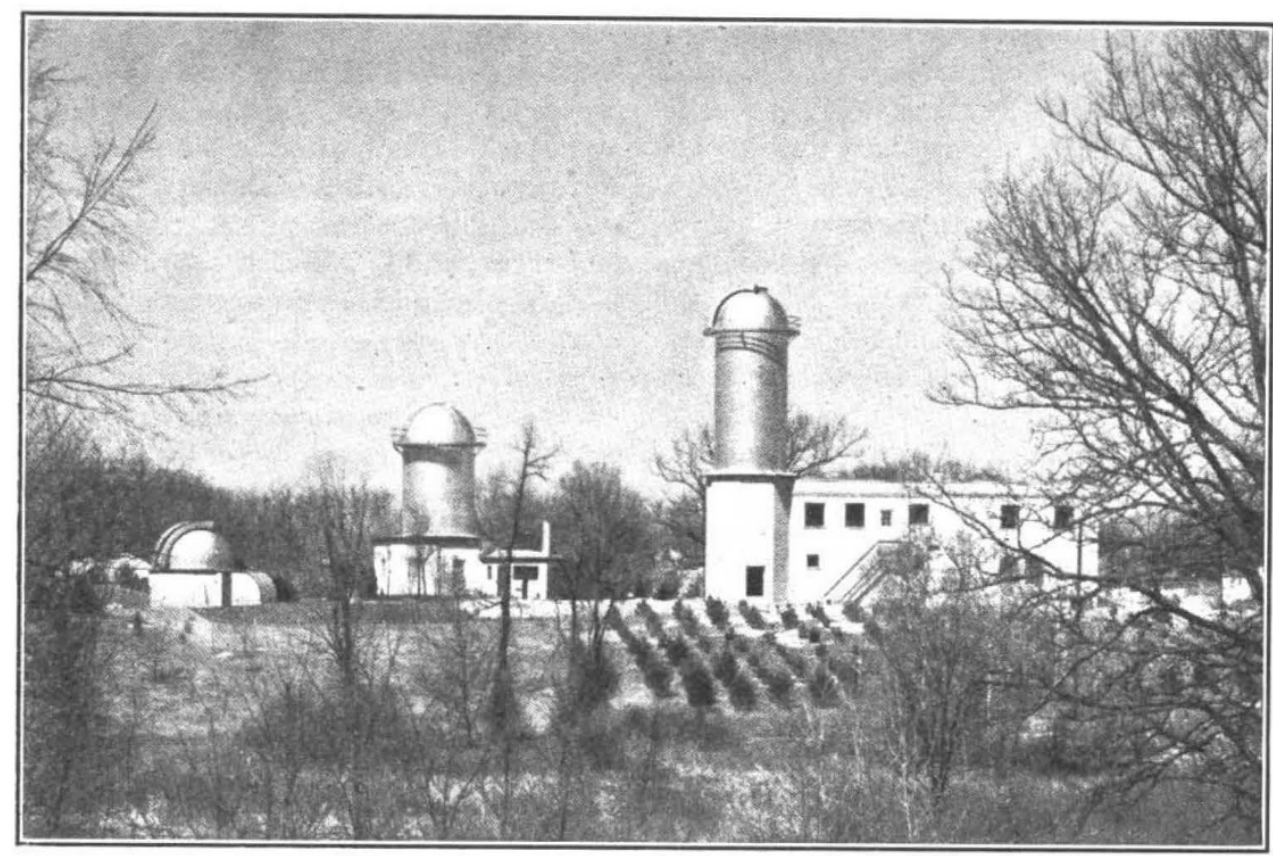

McMath-Hulbert Observatory from the south-east. The New MoGregor Building AND 70-FT. LOWER TELESCOPE IS AT THE RIGHT.

the study of the sun. This new addition brings to a total of three the buildings of the Observatory, located at Lake Angelus, Pontiac, Michigan ; and besides affording opportunities for studies of the heat, magnetic, and other energy conditions of the solar surface, gives the Observatory much-needed working and office space together with a beautifully equipped modern machine and instrument shop.

The new building is two stories in height, covering an area of 5,600 sq. $\mathrm{ft}$., with the tower forming part of the building at the south. On the first floor is a drafting room, the machine and instrument shop, small film storage, cutting, and dark rooms, and a long laboratory room. The offices are on the second floor, as well as a measuring room, a large dark room with unusually complete equipment for photographic work, a second long laboratory, and the library with a projection booth for showing motion picture films of solar phenomena for study. structural elements, and an electrically driven steel elevator which rises in the space between the two towers to carry apparatus to the dome-level. The inner tower carries only the telescopic lightgathering mechanism (colostat), which receives the light from the sun and sends it vertically downward in the inner tower and through the various optical parts of the tower telescope proper. Openings in the two steel towers at the levels of the first and second stories make it possible to send the sunlight gathered by the cœlostat mirrors horizontally in to the various pieces of apparatus in either of the two long laboratory and observing rooms which form lateral extensions of the tower. The machinery of the cœlostat in the dome and for other optical parts is not yet in place, but will be made in the instrument shop where any delicate piece of apparatus, large or small, can be quickly constructed. 
The promise of these facilities for further progress in the studies of the sun is very great. Previously, the Observatory had been impeded by lack of working space. The McMath-Hulbert Observatory was started as an amateur undertaking in 1929 by Robert R. McMath, the director ; Judge Henry S. Hulbert; and the late Francis C. McMath. At that time there was only a $10 \frac{1}{2}$-in. reflecting telescope, housed in the smallest and lowest of the present domes. This was presented to the University of Michigan in 1931. Soon after this, a spectroheliokinematograph was attached to this $10 \frac{1}{2}$-in. reflector ; the first successful motionpicture of a solar prominence, though now regarded as rather crude in comparison with more recent results, was secured in early August 1932, and it was soon evident that many short-lived solar phenomena could be photographed, the existence of which had not been hitherto suspected. As a result, in 1936, the $50-\mathrm{ft}$. tower telescope was erected exclusively for solar studies. During the past four years, more than 400,000 individual pictures or 'frames' have been taken with this powerful instrument, and have yielded results of great interest and value. But most of the work of design and the study of results had to be carried on in the basement of Dr. McMath's residence. This will be overcome with the greater convenience and efficiency secured through adequate facilities in the new building.

The true purpose of the new unit, however, involves even more technical considerations. The work done in the 50 -ft. tower has yielded many films of motions of solar prominences through the development of an ingenious motion picture technique by Dr. McMath. The results have been in two dimensions, and from them a vast amount of evidence has been accumulated as to the character of the motions and changings on the turbulent surface of the sun, but a full study of these motions and of the forces producing them requires much more. During the past year, by means of small shifts in the lines of the spectrum due to velocities in the line of sight, motions in the third direction, that directly toward or away from the earth, have been recorded.

Many questions still remain unanswered, however. It is hoped to determine the temperatures of the streams of flaming materials, speeds of which have been discovered to be so great as ten to fifty or more miles per second. Of even greater importance, more accurate knowledge is sought of the magnetic and electrical conditions accompanying these solar storms, for the manifestations may have a connexion with such familiar phenomena as the aurora, magnetic storms, and interference with radio reception. Other considerations to be studied are the discovery of the heat changes, degree of electrical and magnetic force involved, and the determination as to whether or not the sun's output of ultra-violet light increases at such times. The instruments to be installed in the McGregor Building and the 70-ft. tower telescope will thus be much more in the field of physics than astronomy.

These are all matters relating to the actual nature and cause of solar activity-to the sources of energy and possible terrestrial effects of the movements shown on the solar films. The ways and means of research into these problems are by no means perfectly clear. Unforeseen difficulties may arise. But whatever the results, a powerful instrument is needed for the purpose of studying, through the most advanced techniques of modern physics and astronomy, these energy relations, and searching for the real reasons behind solar phenomena. What discoveries will be made no one knows, but they are sure to be of great scientific interest and value, perhaps even with a more practical terrestrial application.

The MeGregor Building and Tower are so named in memory of the late Tracy W. McGregor, founder of the McGregor Fund, which has provided funds for the construction of this powerful research plant and has also made a grant for part of the support of this work during the coming five-year period.

\title{
ULTRA-VIOLET AND ELECTRON MICROSCOPY*
}

\author{
By Prof. L. C. Martin, \\ IMPERIAL College of SCIENCE, LONDON
} THE compound microscope has now been and fifty years, but the development of the instrument has been curiously spasmodic in spite of its admitted importance. The earliest models were

* Substance of a Friday evening discourse delivered at the Royal Institution on May 24. perhaps looked on as little more than toys, and it was not until the publication of Hooke's "Micrographia" that the possibilities were better appreciated. Even so, it seems as if the optical design of the microscope remained for a hundred years largely as Hooke left it.

It became evident during the development of 